\title{
Reconocimiento de la COVID-19 como enfermedad profesional y su repercusión en diferentes colectivos profesionales
}

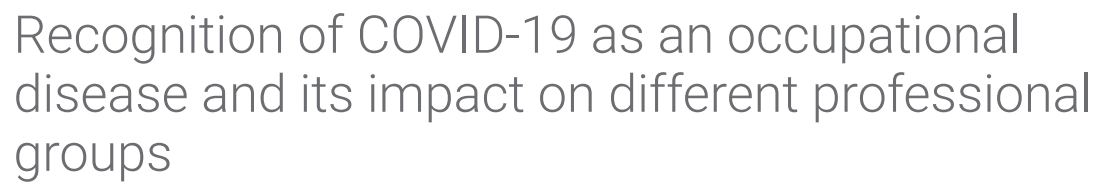

Juan José Agún González [D 0000-0002-2677-7198

Raúl Aguilar ${ }^{1}$ (D) 0000-0001-8656-8155

${ }^{1}$ Universidad Internacional de Valencia, Valencia, España.

Fechas - Dates

Recibido: 2021.04.28

Aceptado: 2021.05.25

Publicado: 2021.07.15
Correspondencia · Corresponding Author

Juan José Agún

Correo electrónico: juanjose.agun@campusviu.es 
En la notificación no 366 "Enfermedad de Coronavirus" publicada por el Ministerio de Sanidad en fecha 03/05/2021, con los datos individualizados notificados por las CCAA a la Red Nacional de Vigilancia Epidemiológica (al sistema SiViEs), se indica que están notificados en España 3540430 casos de COVID-19 de los cuales 78293 son fallecidos ${ }^{(1)}$. Del total de casos notificados, corresponden al personal sanitario y sociosanitario unos 80065 (2.26\%) casos de COVID-19 notificados con diagnóstico posterior al 10 de mayo de $2020^{(2)}$, siendo significativamente mayor el porcentaje entre las mujeres (77.95\% o 62416 casos) que entre los hombres (21.95\% o 17582 casos). Además, a la cifra de 80.065 casos se deben sumar un total de 35.548 casos declarados desde el inicio de la pandemia hasta el 7/05/2020(3), obteniendo una cifra total de 115613 casos notificados de COVID-19 en personal sanitario.

El Ministerio de Sanidad establece que: "Con la evidencia científica acumulada, se considera que SARS-CoV-2 puede transmitirse de persona a persona por diferentes vías, siendo la principal mediante el contacto y la inhalación de las gotas y aerosoles respiratorios emitidos por un enfermo hasta las vías respiratorias superiores e inferiores de una persona susceptible. También se puede producir el contagio por contacto indirecto a través de las manos u objetos contaminados las secreciones respiratorias del enfermo con las mucosas de las vías respiratorias y la conjuntiva del susceptible. La transmisión vertical a través de la placenta también es posible, aunque poco frecuente. Otras vías de transmisión son muy improbables"(4).

Por lo tanto, se puede entender que al ser una enfermedad infectocontagiosa, puede afectar a numerosos profesionales sanitarios y no sanitarios que están en contacto directo con pacientes de COVID-19.

Al inicio de la pandemia, las todas las incapacidades temporales producidas por el SARS-Cov-2 fueron consideradas como enfermedad común, sin embargo en la última actualización del Real Decreto-Ley 6/2020, de 10 de marzo, se ha modificado esta contingencia en su artículo 5 indicando que "al objeto de proteger la salud pública, se considerarán, con carácter excepcional, situación asimilada a accidente de trabajo, exclusivamente para la prestación económica de incapacidad temporal del sistema de Seguridad Social, aquellos periodos de aislamiento o contagio de las personas trabajadoras provocados por el virus COVID-19, salvo que se pruebe que el contagio de la enfermedad se ha contraído con causa exclusiva en la realización del trabajo en los términos que señala el artículo 156 del texto refundido de la Ley General de la Seguridad Social, aprobado por el Real Decreto Legislativo 8/2015, de 30 de octubre, en cuyo caso será calificada como accidente de trabajo"(5).

Posteriormente el Real Decreto-Ley 28/2020, de 22 de septiembre, estableció en la Disposición Adicional cuarta que:

"1. Desde la declaración de la pandemia internacional por la Organización Mundial de la Salud y hasta que las autoridades sanitarias levanten todas las medidas de prevención adoptadas para hacer frente a la crisis sanitaria ocasionada por el COVID-19, las prestaciones de Seguridad Social que cause el personal que presta servicios en centros sanitarios o socio-sanitarios, inscritos en los registros correspondientes, y que en el ejercicio de su profesión, hayan contraído el virus SARS-CoV2 
por haber estado expuesto a ese riesgo específico durante la prestación de servicios sanitarios y socio-sanitarios, cuando así se acredite por los servicios de Prevención de Riesgos laborales y Salud Laboral, se considerarán derivadas de accidente de trabajo, al entender cumplidos los requisitos exigidos en el artículo 156.2.e) del texto refundido de la Ley General de la Seguridad Social, aprobado por el Real Decreto Legislativo 8/2015, de 30 de octubre.

2. El contagio y padecimiento de la enfermedad se acreditará mediante el correspondiente parte de accidente de trabajo que deberá haberse expedido dentro del mismo periodo de referencia.

3. En los casos de fallecimiento, se considerará que la causa es accidente de trabajo siempre que el fallecimiento se haya producido dentro de los cinco años siguientes al contagio de la enfermedad y derivado de la misma, de conformidad con lo dispuesto en el artículo 217.2 del texto refundido de la Ley General de la Seguridad Social"(6)

Por lo tanto y a tenor de lo expuesto en la normativa de referencia, las Mutuas Colaboradoras de la Seguridad Social han tenido que establecer cinco requisitos para la declaración de enfermedad profesional:

- Debe estar acreditado el contagio por COVID-19.

- El contagio por COVID-19 se haya producido en fecha posterior al 11 de marzo de 2020.

- El servicio de prevención de riesgos laborales ha determinado que el contagio por COVID-19 se ha producido dentro del centro de trabajo y en el ejercicio de su profesión, prestando servicios sanitarios o sociosanitarios.

- El centro de trabajo en el que lleva a cabo su ejercicio profesional es un centro sanitario o sociosanitario (CNAEs 8610, 8621, 8622, 8690 y 8710) y está inscrito en el registro del ministerio( ${ }^{(7)}$.

- La prestación de servicios propios de su profesión, a efectos de la prestación solicitada, son considerados sanitarios o sociosanitarios.

Según lo establecido anteriormente, la declaración de enfermedad profesional exclusivamente existe para el personal sanitario y en ningún caso para los trabajadores no sanitarios de un centro sanitario o sociosanitario, afirmación refrendada por el Criterio 22/20220 de la Subdirección General de Ordenación y Asistencia Jurídica de 18 de noviembre "No se consideran derivadas de accidente de trabajo las prestaciones del sistema de la Seguridad Social causadas por el personal que trabajando en centros sanitarios o socio-sanitarios desempeñe otras funciones distintas a la prestación de servicios sanitarios y socio-sanitarios (a título de ejemplo se puede mencionar: el personal administrativo, el personal de limpieza, celadores, etc. $)^{\prime \prime(8)}$.

Es evidente que, en esta situación de pandemia, no solo se han visto afectados por COVID-19 el personal sanitario y sociosanitario ya que existen multitud de profesiones que realizan su trabajo de forma directa con enfermos (pacientes, 
acompañantes y trabajadores/as) de COVID-19 y por lo tanto expuestos a riesgo de contraer la enfermedad en la realización de su actividad profesional no sanitaria. Entre otros, podemos señalar a los técnicos de prevención y responsables de los servicios de prevención propios o mancomunados no sanitarios, personal de limpieza, mantenimiento, celadores, etc.

Todo este personal no sanitario ha estado expuesto a situaciones de trabajo con riesgo de exposición a "contacto y la inhalación de las gotas y aerosoles respiratorios emitidos por un enfermo hasta las vías respiratorias superiores e inferiores de una persona susceptible. También se puede producir el contagio por contacto indirecto a través de las manos u objetos contaminados las secreciones respiratorias del enfermo con las mucosas de las vías respiratorias y la conjuntiva del susceptible ${ }^{\prime \prime(4)}$.

Así mismo, teniendo en cuenta que las enfermedades profesionales se regulan en el artículo 157 del Real Decreto Legislativo 8/2015 “Se entenderá por enfermedad profesional la contraída a consecuencia del trabajo ejecutado por cuenta ajena en las actividades que se especifiquen en el cuadro que se apruebe por las disposiciones de aplicación y desarrollo de esta ley, y que esté provocada por la acción de los elementos o sustancias que en dicho cuadro se indiquen para cada enfermedad profesional"(9). Siendo el Real Decreto 1299/2006, de 10 de noviembre, por el que se aprueba el cuadro de enfermedades profesionales en el sistema de la Seguridad Social y se establecen criterios para su notificación y registro, el que indica textualmente en la Tabla 1: "Enfermedades infecciosas causadas por el trabajo de las personas que se ocupan de la prevención, asistencia médica y actividades en las que se ha probado un riesgo de infección (excluidos aquellos microorganismos incluidos en el grupo 1 del R.D. 664/1997, de 12 de mayo regulador de la protección de los trabajadores contra los riesgos relacionados con la exposición a agentes biológicos durante el trabajo)" estando en este cuadro incluido, en el código 3a0104, el "Personal no sanitario, trabajadores de centros asistenciales o de cuidados de enfermos, tanto en ambulatorios como en instituciones cerradas o a domicilio"(10).

No podemos olvidar que el Real Decreto 664/1997 establece en su art. 3, como "Agente biológico del grupo 3: aquél que puede causar una enfermedad grave en el hombre y presenta un serio peligro para los trabajadores, con riesgo de que se propague a la colectividad y existiendo generalmente una profilaxis o tratamiento eficaz"(11), y que recientemente se ha incluido, en la actualización publicada el 10/12/2020, en el Anexo II de Clasificación de agentes biológicos como grupo 3 : "Coronavirus del síndrome respiratorio agudo grave 2 (SARS-CoV-2)"(12).

En definitiva, si el virus SARS-CoV-2 que produce la enfermedad de COVID-19, es un agente biológico del grupo 3 , reconocido como enfermedad profesional del personal sanitario y no sanitario pero excluido de las contingencias profesionales según el criterio del Instituto Nacional de la Seguridad Social ¿por qué no se considera accidente al resto de profesionales? O mejor dicho, ¿por qué no se consideran estos contagios como enfermedad profesional como con el resto de agentes biológicos? 
El personal no sanitario de los hospitales, centros de salud y sociosanitarios, como colectivo profesional, están expuestos al riesgo biológico del SARS-CoV-2 pero no se reconoce la contingencia como enfermedad profesional pese a tener un amplio ordenamiento legal que los ampara. Desconociendo la razón, esperamos que en breve las autoridades competentes enmienden esta situación incluyendo a los profesionales no sanitarios, que han padecido COVID-19, arriesgando su vida igual que el personal sanitario, dentro de la contingencia profesional adecuada.

\section{Bibliografía}

1. Actualización no 366. Enfermedad por el coronavirus (COVID-19). 03.05.2021 [actualizado 6 Jul 2021; citado 6 Jul 2021]. Disponible en: https://www.mscbs.gob. es/profesionales/saludPublica/ccayes/alertasActual/nCov/documentos/Actualizacion_366_COVID-19.pdf

2. Red Nacional de Vigilancia Epidemiológica. Informe n 76. Situación de COVID-19 en España. Casos diagnosticados a partir 10 de mayo Informe COVID-19. 28 de abril de 2021. [actualizado 6 Jul 2021; citado 6 Jul 2021]. Disponible en: https://www.isciii.es/QueHacemos/Servicios/VigilanciaSaludPublicaRENAVE/EnfermedadesTransmisibles/Documents/INFORMES/Informes COVID-19/INFORMES COVID-19 2021/Informe COVID-19. N\%C2\%BA 76_28 de abril de 2021.pdf

3. Red Nacional de Vigilancia Epidemiológica. Informe sobre la situación de COVID-19 en personal sanitario en España. 07-05-2020. [actualizado 6 Jul 2021; citado 6 Jul 2021]. Disponible en: https://www.isciii.es/QueHacemos/Servicios/ VigilanciaSaludPublicaRENAVE/EnfermedadesTransmisibles/Documents/INFORMES/Informes\%20COVID-19/COVID-19\%20en\%20Espa\%C3\%B1a.\%20Situaci\%C3\%B3n\%20en\%20Sanitarios\%20a\%2007\%20de\%20mayo\%20de\%202020.pdf

4. Ministerio de Sanidad. información científica-técnica. Transmisión de SARSCoV-2. [actualizado 25 Mar 2021; citado 6 Jul 2021]. Disponible en : https://www. mscbs.gob.es/profesionales/saludPublica/ccayes/alertasActual/nCov/documentos/Documento_TRANSMISION.pdf

5. Real Decreto-ley 6/2020, de 10 de marzo, por el que se adoptan determinadas medidas urgentes en el ámbito económico y para la protección de la salud pública. [actualizado 6 Jul 2021; citado 6 Jul 2021]. Disponible en: Real Decreto-ley 6/2020, de 10 de marzo, por el que se adoptan determinadas medidas urgentes en el ámbito económico y para la protección de la salud pública. (boe.es)

6. Real Decreto-ley $28 / 2020$, de 22 de septiembre, de trabajo a distancia. [actualizado 6 Jul 2021; citado 6 Jul 2021]. Disponible en: Real Decreto-ley 28/2020, de 22 de septiembre, de trabajo a distancia. (boe.es)

7. Registro General de centros, servicios y establecimientos sanitarios. [actualizado 6 Jul 2021; citado 6 Jul 2021]. Disponible en: http://regcess.mscbs.es/regcessWeb/inicioBuscarCentrosAction.do 
8. Criterio 22/20220 de la Subdirección General de Ordenación y Asistencia Jurídica de 18 de noviembre. Disponible en: https://www.comv.es/wp-content/uploads/2020/11/CRITERIO-22_2020-CONTINGENCIA-CONTAGIO-COVID-19-EN-PERSONAL-SANITARIO.pdf

9. Real Decreto Legislativo $8 / 2015$, de 30 de octubre, por el que se aprueba el texto refundido de la Ley General de la Seguridad Social. Disponible en: https://www. boe.es/buscar/pdf/2015/BOE-A-2015-11724-consolidado.pdf

10. Real Decreto 1299/2006, de 10 de noviembre, por el que se aprueba el cuadro de enfermedades profesionales en el sistema de la Seguridad Social y se establecen criterios para su notificación y registro. Disponible en: https://www.boe.es/ buscar/act.php?id=BOE-A-2006-22169

11. Real Decreto 664/1997, de 12 de mayo, sobre la protección de los trabajadores contra los riesgos relacionados con la exposición a agentes biológicos durante el trabajo. Disponible en: https://www.boe.es/buscar/pdf/1997/ BOE-A-1997-11144-consolidado.pdf

12. Orden TES/1180/2020, de 4 de diciembre, por la que se adapta en función del progreso técnico el Real Decreto 664/1997, de 12 de mayo, sobre la protección de los trabajadores contra los riesgos relacionados con la exposición a agentes biológicos durante el trabajo. Disponible en: https://www.boe.es/boe/dias/2020/12/10/ pdfs/BOE-A-2020-15871.pdf 